\title{
OVINOCULTURA LEITEIRA NO BRASIL: ASPECTOS E FATORES RELACIONADOS À COMPOSIÇÃO, AO CONSUMO E À LEGISLAÇÃO
}

Ivandre Antonio Merlin Junior, Renan Grecco Costa, Ligia Grecco Costa, Agostinho Ludovico, Fabiola Cristiane de Almeida Rego, Lina Casale Aragon-Alegro, Elsa Helena Walter de Santana

Universidade Norte do Paraná - UNOPAR, Mestrado em Ciência e Tecnologia do Leite e Derivados, Mestrado em Saúde e Produção de Ruminantes, Curso de Biomedicina, Londrina, PR. E-mail: ivandrejunior@terra.com.br

\section{RESUMO}

Ao longo dos últimos anos a ovinocultura leiteira vem ganhando espaço no mercado internacional e nacional brasileiro. Desta forma, esta revisão teve como objetivo projetar um delineamento da ovinocultura leiteira brasileira, com enfoque nos aspectos da legislação, da composição e da qualidade do leite. Sua exploração mostra-se bastante vantajosa e rentável, visto que, o leite de ovelha carrega consigo características tecnológicas importantes para a indústria de alimentos. Seu elevado potencial de ser transformado em derivados lácteos, que agregam alta qualidade nutricional, atrai investidores e consumidores. As altas concentrações de sólidos totais presentes no leite de ovelha permitem a formulação de queijos, iogurtes e manteigas, de rentabilidade superior a de outras espécies. Fatores como a raça, a alimentação, a estação do ano, o estágio de lactação e o estado sanitário são variáveis que influ enciam diretamente na composição do leite de ovelha. No Brasil, ainda não existe legislação específica para controle da qualidade do leite de ovinos, o que demonstra a necessidade de sua criação. São poucos os estudos brasileiros que caracterizam a composição e qualidade do leite de ovelha produzido no Brasil, sendo assim, importante o estudo das suas características e fatores que determinam sua composição.

Palavras-chave: características; físico-químico; leite de ovelha; microbiologia; parâmetros.

\section{DAIRY SHEEP INDUSTRY IN BRAZIL: ASPECTS AND FACTORS RELATED TO THE COMPOSITION, CONSUMPTION AND LEGISLATION}

\begin{abstract}
Over the past few years, the dairy sheep industry have been taking space in the Brazilian national and international market. In this way, this work aimed to design a delineation of the Brazilian dairy sheep industry, with focus on aspects of the legislation, the composition and quality of milk. The explore shows up quite advantageous and profitable, since the sheep's milk carries technological characteristics important for the food industry. Their high potential to be transformed into milk products, that add high nutritional quality, attracts investors and consumers. The high concentrations of total solids present in the sheep milk allow the formulation of cheeses, yogurts and butters, of higher profitability than other species. Factors like the breed, feed, the season, the stage of lactation and the health status are variables that directly influence on composition of sheep's milk. In Brazil, there is still no specific legislation to control the quality of sheep milk, which demonstrates the necessity of its creation. There are few Brazilian studies that characterize the composition and quality of sheep milk produced in Brazil, being important the study of its characteristics and factors that determine its composition.
\end{abstract}

Keywords: characteristics; microbiology; sheep milk; parameters; physicochemical.

\section{INTRODUÇÃO}

A produção de leite, em todo o mundo, ultrapassou 750 milhões de toneladas no ano de 2012, sendo cerca de 10 milhões de toneladas oriundas de ovinos (FAO, 2013). A maioria do leite ovino é produzido na China, Turquia e Grécia e também tem importância na África. Os produtos lácteos ovinos são encontrados com frequência nos mercados de países como China, Síria, Iran, Turquia e Argélia (FAO, 2015).
No Brasil a ovinocultura, enquanto agronegócio, já alcançou o montante de 17,6 milhões de cabeças. Em ordem decrescente, do número de animais, têm-se a região Nordeste $(57,2 \%)$ com expressivos valores, seguida das regiões Sul $(28,0 \%)$, Centro-Oeste $(6,9 \%)$, Sudeste $(4,3 \%)$ e Norte (3,6\%) (IBGE, 2012). Atualmente, a produção de leite ovino, além do Rio Grande do Sul, alcança os Estados de Santa Catarina e Minas 
Gerais e está associada a queijos e iogurtes (ROHENKOHL et al., 2011).

O leite de ovelha apresenta riqueza em seus constituintes, quando comparado com o de outras espécies, sendo mais concentrado em sólidos totais e, especialmente, rico em gordura e proteínas como a caseína. Tais características são marcantes na produção de queijos duros e macios, gerando sabores e texturas de alto valor mercadológico (ASSENAT, 1985; RIBEIRO et al., 2007).

Em termos de jurisprudência, o Brasil não conta com uma regulamentação exclusiva para o leite ovino, apresentando apenas publicações generalistas como a Instrução Normativa 62/2011 que visa regulamentar a produção, identidade e qualidade do leite (com exceção do de cabra) instituindo prazos para aplicação dos padrões de países mais exigentes (BRASIL, 2011).

Esta revisão tem como objetivo traçar um perfil da ovinocultura leiteira no Brasil, destacando aspectos da legislação, composição e qualidade do leite.

\section{A OVINOCULTURA LEITEIRA NO MUNDO}

Segundo estatísticas da FAO - Food and Agriculture Organization of the United Nations (FAO, 2013), a produção mundial de leite de ovelha, em 2011, foi de 9.262.607 toneladas. No ano de 2009 o Brasil contribuiu com 143.768 toneladas de leite caprino (FAO, 2014).

Dentre os maiores produtores de leite de ovelha destacam-se os países do Mediterrâneo, participando com aproximadamente $48 \%$ da produção mundial, porém, praticamente, não há consumo deste na forma fluida, sendo a maior parte transformada em queijos e, uma pequena parte, em iogurte, sobretudo na Grécia (TALEVSKI et al., 2009; BERGAMINI et al., 2010).

Segundo Haenlein (2007), a produção de leite de ovelhas não visa à obtenção de volume de leite fluido, mas sim um produto diferenciado, com alta concentração de sólidos, com vistas à produção de produtos lácteos. A ovelha é capaz de produzir, em um menor período de lactação, uma maior quantidade de sólidos por litro de leite em relação às demais espécies (Tabela 1 ).

Tabela 1. Comparação entre o período de lactação, produção média de leite e gordura entre diversas raças ovinas de diferentes localidades.

\begin{tabular}{|c|c|c|c|c|}
\hline \multirow{2}{*}{ País } & \multirow{2}{*}{ Raça } & \multirow{2}{*}{ Duração da lactação (dias) } & \multicolumn{2}{|c|}{ Produção (Kg) } \\
\hline & & & Leite & Gordura \\
\hline Tchecoslováquia & Pramenka & 162 & 162 & 12 \\
\hline \multirow{2}{*}{ França } & Lacaune & 165 & 270 & 20 \\
\hline & Corsica & 170 & 108 & 9 \\
\hline Alemanha & East Friesian & 300 & 632 & 41 \\
\hline \multirow{5}{*}{ Grécia } & Chios & 210 & 218 & 17 \\
\hline & Karagouniki & 168 & 142 & 12 \\
\hline & Kymi & 192 & 135 & 11 \\
\hline & Sfakia & 195 & 132 & 12 \\
\hline & Skopelos & 170 & 158 & 14 \\
\hline \multirow{2}{*}{ Israel } & Israeli Awassi & 270 & 495 & 33 \\
\hline & Assaf & 180 & 180 & 13 \\
\hline \multirow{4}{*}{ Itália } & Comisana & 150 & 132 & 11 \\
\hline & Langhe & 150 & 115 & 10 \\
\hline & Massese & 150 & 125 & 10 \\
\hline & Sarda & 200 & 158 & 11 \\
\hline \multirow{4}{*}{ Espanha } & Canaria & 200 & 180 & 14 \\
\hline & Churra & 150 & 150 & 11 \\
\hline & Lacha & 180 & 210 & 16 \\
\hline & Manchega & 210 & 300 & 28 \\
\hline Turquia & Awassi & 120 & 168 & 11 \\
\hline
\end{tabular}

Fonte: Adaptado de Haenlein (2007).

Uma importante característica do leite de ovelha é a sua capacidade de transformar-se em queijos de alta qualidade sensorial e nutricional, com excelente rendimento (BENCINI, 2002; 
MORAND-FEHR et al., 2007). Por esse motivo, diversos países, principalmente na Europa, produzem queijos de leite de ovelha, sendo que muitos são típicos de determinadas regiões, recebendo das autoridades da Comunidade Econômica Europeia, certificação e proteção da designação por origem ou identificação geográfica, pois algumas características destes produtos não podem ser fielmente reproduzidas em outros locais (SCINTU; PIREDDA, 2007). De acordo com Pulina et al. (2006) um dos motivos, que justifica tal fato, é a composição botânica das pastagens que influencia os aromas observados no leite, conferindo características aos queijos produzidos (Tabela 2).

Tabela 2. Principais queijos de ovelhas típicos de determinadas regiões do mundo.

\begin{tabular}{|c|c|}
\hline País & Queijo \\
\hline \multirow{3}{*}{ França } & Roquefort \\
\hline & Abbaye de Belloc \\
\hline & Perail \\
\hline \multirow{3}{*}{ Itália } & Canestrato Pugliese \\
\hline & Fiore Sardo \\
\hline & Pecorino Romano/ Sardo/ Toscano \\
\hline \multirow{2}{*}{ Inglaterra } & $\begin{array}{l}\text { Friesla } \\
\end{array}$ \\
\hline & Olde York \\
\hline Irlanda & Orla \\
\hline \multirow{5}{*}{ Espanha } & Castellano \\
\hline & Idiazabal \\
\hline & Manchego \\
\hline & Roncal \\
\hline & Zamorano \\
\hline Portugal & Serra da Estrela \\
\hline \multirow{3}{*}{ Grécia } & Kefalotiri \\
\hline & Myzithra \\
\hline & Feta* \\
\hline \multirow{2}{*}{ Turquia } & Beyaz Peynir \\
\hline & Mihalic Peynir \\
\hline República Tcheca & Abertam \\
\hline Romênia & Brinza \\
\hline Bulgária & Katschkawalj (casco de cavalo) \\
\hline Hungria & Liptoi \\
\hline \multirow{3}{*}{ Líbia } & Al Zahra \\
\hline & Jibnet Grus \\
\hline & Al Naseem \\
\hline
\end{tabular}

*Feito com leite de ovelha ou de vaca.

Fonte: Harbutt, 1999 apud Campos, 2011.

A produção de ovelhas leiteiras é tradicional na França, especialmente nas áreas montanhosas localizadas ao sul do país. Em 1999, foram produzidos 234 milhões de litros de leite de ovelha, sendo $76 \%$ do total na região de Roquefort, onde a raça Lacaune foi a principal linhagem leiteira utilizada. Na década de 1960, a produção encontrava-se estagnada em torno de 57 milhões de litros e a raça, criada então para dupla aptidão (carne e leite), apresentava baixa produção. Foram desenvolvidos e implementados programas de melhoramento genético e de manejo para toda a população ovina, objetivando, não só a produção em volume, mas também maiores teores de proteína e gordura. A raça Lacaune foi melhorada, sobretudo nas décadas de 1970 a 1990, evoluindo de uma média em torno dos 100 litros por lactação, para médias superiores a 270 litros (BARILLET et al., 2001). 


\section{A OVINOCULTURA LEITEIRA NO BRASIL}

O trabalho com leite de ovelhas foi introduzido, no Brasil, em 1992, por intermédio da importação de animais da raça francesa Lacaune no Rio Grande do Sul, que se adaptaram muito bem às condições climáticas e alimentares no sul do país. Em pico de lactação - cerca de 30 dias pós-parto - uma fêmea Lacaune pode produzir até 4,5 litros de leite por dia. Verifica-se uma média de 1,3 litros/dia em criações no Rio Grande do Sul, para um período médio de lactação de 160 dias (BRITO et al., 2006). A raça Bergamácia, de origem Italiana, foi introduzida no país em 1930, e inicialmente foi explorada para carne e lã. A exploração leiteira hoje se concentram nas regiões centrais do país e Nordeste. Em 2007 foi introduzida uma raça de origem alemã, a East Friesian ou Milchschaf, pela Fazenda Valle das Fadas, localizada em Campos do Jordão, estado de São Paulo. Esta raça inicialmente foi explorada na Argentina e Uruguai (GRIEBLER, 2012) e vêm se difundindo no pais nos estados Paraná, Santa Catarina e Rio Grande do Sul devido à rusticidade, boa produção de leite e número de cordeiros desmamados (AGUINSKI, 2011; TICIANI et al., 2013).

Apesar de ser uma atividade nova no país, a ovinocultura leiteira vem, gradativamente, conquistando adeptos, motivados principalmente pelas características do leite ovino: aptidão à fabricação de produtos lácteos de qualidade e com excelente rendimento (BENCINI, 2002). No ano de 2008 a estimativa de processamento de leite de ovelha, no Brasil, foi de 509.000 litros (ROHENKOHL et al., 2011). Mais recentemente, avalia-se uma produção de aproximadamente 800.000 litros de leite de ovelha por ano, contando ainda, com a recente introdução de uma segunda raça de ovelha leiteira, de origem alemã: a East Friesian (NASCIMENTO, 2013), também conhecida como Milchschaf (no Uruguai) ou Frisona (na Argentina).

Com apoio da EMBRAPA (Empresa Brasileira de Pesquisa Agropecuária), do SEBRAE$\mathrm{SC}$ (Serviço Brasileiro de Apoio às Micro e Pequenas Empresas de Santa Catarina), e do SENAI-SC (Serviço Nacional de Aprendizagem Industrial de Santa Catarina), a pouco, foi criada a Associação Brasileira de Criadores de Ovinocultura de Leite. Dentre diversas discussões, a Associação estuda a produção de leite ovino em pó e a importação de matrizes leiteiras (WOEHL, 2011). No Brasil já existem laticínios voltadas especificamente para o beneficiamento deste leite, que são inspecionadas pelo SIF - Serviço de Inspeção Federal e produtores de queijos habilitados para exportação (BRASIL, 2015). Os principais queijos produzidos no Brasil com Serviço de Inspeção Federal (SIF) são os Tipos Pecorino Toscano Fresco e Maturado, queijo Fascal, Tipo Feta, Tipo Roquefort, Ricota Fresca (GRIEBLER, 2012). Em 2013, no município de São Lourenço, Minas Gerais, deu-se início as atividades do primeiro laticínio daquele estado para produção de queijos de ovelha com selo de Inspeção Federal (SIF), com capacidade de processamento diário de 1.500 litros de leite, sendo 700 litros diários provenientes de criatório próprio (SEAPA, 2013).

\section{A LEGISLAÇÃO NO PAÍS}

No Brasil, ao início da década de 50, começaram a surgir as primeiras discussões a cerca das regras que o leite de ovelha deveria seguir. Entretanto, devido o baixo volume de produção, a legislação, inicialmente, era bastante inespecífica, como pode ser observado no Regulamento da Inspeção Industrial e Sanitária de Produtos de Origem Animal - RIISPOA, de 1952, que define, em seus artigos 480 e 481, respectivamente, "a produção de leite das espécies caprina, ovina e outras, fica sujeita às mesmas determinações do presente Regulamento satisfeitas as exigências para sua identificação" e que "a composição média do leite das espécies caprina, ovina e outras, bem como as condições de sua obtenção, serão determinadas quando houver produção intensiva desse produto" (BRASIL, 1952).

Em 1998, o Governo brasileiro instituiu um grupo de trabalho, visando estudar e propor medidas que melhorassem a qualidade do leite produzido no país (BRASIL, 1998). Assim, em 2000, foi instituído o Regulamento Técnico de Produção, Identidade e Qualidade do Leite de Cabra (BRASIL, 2000), e em 2002, foi publicada a Instrução Normativa (IN) 51 (BRASIL, 2002) que regulamentou a produção, identidade e qualidade do leite, exceto o de cabra, criando prazos para aplicação de padrões de qualidade comparáveis aos dos países mais exigentes. Mais recentemente, a IN 51 foi substituída pela Instrução Normativa 62/2011 (BRASIL, 2011), que promoveu pequenas alterações na legislação e prorrogou os prazos para aplicação dos padrões de qualidade estabelecidos na IN 51. A Tabela 3 
apresenta os requisitos de qualidade definidos na IN 62/2011 para leite (exceto leite de cabra como definido na normativa) e na IN 37/2000, para leite de cabra.

Tabela 3. Requisitos físico-químicos e microbiológicos instituídos pelas IN 62/2011 (leite de vaca) e IN $37 / 2000$ (leite de cabra).

\begin{tabular}{|c|c|c|}
\hline \multirow{2}{*}{ Requisitos } & \multicolumn{2}{|l|}{ Limites } \\
\hline & IN 62/2011 & IN 37/2000 \\
\hline Matéria Gorda (g/100g) & Teor original com o mínimo de 3,0 & Teor original \\
\hline $\begin{array}{l}\text { Densidade Relativa a } 15 / 15^{\circ} \mathrm{C} \\
\qquad(\mathrm{g} / \mathrm{mL})\end{array}$ & 1,028 a 1,034 & 1,028 a 1,034 \\
\hline $\begin{array}{c}\text { Acidez Titulável (g de ácido } \\
\text { lático/100mL) }\end{array}$ & 0,14 a 0,18 & 0,13 a 0,18 \\
\hline $\begin{array}{l}\text { Extrato Seco Desengordurado } \\
(\mathrm{g} / 100 \mathrm{~g})\end{array}$ & Mínimo de 8,4 & Mínimo de 8,2 \\
\hline Proteína Total (g/100g) & Mínimo de 2,9 & Mínimo de 2,8 \\
\hline Lactose $(\mathrm{g} / 100 \mathrm{~g})$ & ND & Mínimo de 4,3 \\
\hline Cinzas (g/100g) & ND & Mínimo de 0,7 \\
\hline Índice Crioscópico & $-0,530^{\circ} \mathrm{H}$ a $-0,550^{\circ} \mathrm{H}$ & $-0,550^{\circ} \mathrm{H}$ a $-0,585^{\circ} \mathrm{H}$ \\
\hline $\begin{array}{c}\text { Contagem Padrão em Placas } \\
\text { (UFC/mL) }\end{array}$ & Máximo de $6,0 \times 10^{5}$ & Máximo de $5,0 \times 10^{5}$ \\
\hline $\begin{array}{c}\text { Contagem de Células Somáticas } \\
\text { (UFC/mL) }\end{array}$ & Máximo de $6,0 \times 10^{5}$ & ND \\
\hline Teste do Álcool/ Alizarol & $72 \%$ & Não Aplicável \\
\hline $\begin{array}{l}\text { Temperatura máxima de } \\
\text { conservação do leite }\end{array}$ & $\begin{array}{l}\text { Tanques de refrigeração por expansão direta }= \\
4^{\circ} \mathrm{C} \text { (em até } 3 \text { horas após ordenha) } \\
\text { Tanques de refrigeração por imersão }=7^{\circ} \mathrm{C} \\
\text { (em até } 3 \text { horas após ordenha) }\end{array}$ & $\begin{array}{l}4^{\circ} \mathrm{C} \text { (em até } 2 \text { horas } \\
\text { após ordenha) }\end{array}$ \\
\hline
\end{tabular}

Pesquisa de Resíduos de Antibióticos/ outros Inibidores do crescimento microbiano: limites máximos previstos no Programa Nacional de Controle de Resíduos - MAPA

*ND = não definido no Regulamento Técnico.

Fonte: adaptado de Brasil (2000) e Brasil (2011).

Os produtos fabricados a partir do leite de ovelha são registrados pela Divisão de Inspeção de Leite e Derivados (DILEI) do Ministério da Agricultura, Pecuária e Abastecimento (MAPA), com base em literatura científica e outras publicações, devido à inexistência de Regulamento Técnico específico.

\section{COMPOSIÇÃO DO LEITE DE OVELHA}

A água é o principal componente do leite, o qual representa pouco mais de $80 \%$ da composição. É responsável pela manutenção das diferentes fases dos demais elementos em solução e por muitas características físicoquímicas do leite, como a constante dielétrica, a tensão superficial e a condutividade térmica, sendo de grande importância para os processos tecnológicos na produção de produtos lácteos (FOX; MCSWEENEY, 1998).

Comparando-se as informações da composição do leite das diferentes espécies, na Tabela 4, observa-se que o leite ovino apresenta uma diferenciação maior em relação ao leite bovino do que o leite de cabra. $\mathrm{O}$ alto teor de sólidos e as características destes no leite de ovelha justificam seu excepcional rendimento na fabricação de queijos, além de acentuadas diferenças sensoriais e de propriedades de coagulação (BENCINI, 2002; RIBEIRO et al., 2007). 
Tabela 4. Composição média dos nutrientes básicos em leite de cabra, de ovelha, de vaca e humano.

\begin{tabular}{ccccc}
\hline Componente & Cabra & Ovelha & Vaca & Humano \\
\hline Gordura (\%) & 3,8 & $\mathbf{7 , 9}$ & 3,6 & 4,0 \\
\hline Sólidos não gordurosos (\%) & 8,9 & $\mathbf{1 2 , 0}$ & 9,0 & 8,9 \\
\hline Lactose (\%) & 4,1 & $\mathbf{4 , 9}$ & 4,7 & 6,9 \\
\hline Proteína (\%) & 3,4 & $\mathbf{6 , 2}$ & 3,2 & 1,2 \\
\hline Caseína (\%) & 2,4 & $\mathbf{4 , 2}$ & 2,6 & 0,4 \\
\hline Albumina/ Globulina (\%) & 0,6 & $\mathbf{0 , 8}$ & 0,2 & 0,5 \\
\hline Nitrogênio não proteico (\%) & 0,4 & $\mathbf{0 , 8}$ & 0,2 & 0,5 \\
\hline Cinzas (\%) & 0,8 & $\mathbf{0 , 9}$ & 0,7 & 0,3 \\
\hline Energia (Kcal/ 100mL) & 70 & $\mathbf{1 0 5}$ & 69 & 68
\end{tabular}

Fonte: Park et al., 2007.

A existência e as características de muitos produtos lácteos como queijos, iogurtes e manteiga, dependem das propriedades das proteínas, gorduras, lactose e sais que constituem o leite.

As proteínas do leite possibilitam a produção de queijos (caseínas) e de ricotas (proteínas do soro), além de serem fontes de aminoácidos importantes nutricionalmente. Já os lipídios, fonte de energia e de ácidos graxos poliinsaturados, influenciando as propriedades sensoriais conforme a sua quantidade e ponto de fusão.

A lactose apresenta atributos funcionais, estimulando o crescimento entérico de microrganismos, como Bifidobacterium spp.. Funciona como substrato para os processos fermentativos desejáveis na produção de derivados lácteos. O leite de ovelha tem teores de lactose - entre 22 a $27 \%$ dos sólidos totais mais baixos em relação aos sólidos presentes no leite de vaca - entre 33 a 40\%. Entretanto, representa quantidade suficiente para os processos tecnológicos e fermentativos na produção dos produtos lácteos como iogurtes e queijos (ASSENAT, 1985).

A composição de sais interfere diretamente nas tecnologias aplicadas na produção de leites e derivados, bem como, agrega qualidade nutricional (FOX; MCSWEENEY, 1998). Os altos teores de minerais encontrados no leite de ovelha acarretam em maior teor de cinzas em sua composição. No leite ovino, a variação dos componentes é ampla, principalmente quanto aos teores de gordura e proteína, sendo estes sólidos os elementos mais valorizados pela indústria (MADALENA, 2000; BARBANO; LYNCH, 2006). Segundo Talevski et al. (2009), em 270 amostras coletadas em três regiões da República da Macedônia, foram observados valores variando de 5,10 a $9,09 \%$ (média de 7,07\%) no teor de gordura, de 4,93 a $7,04 \%$ (média de $5,89 \%$ ) no teor de proteína e de 15,6 a $21,08 \%$ (média de $18,07 \%$ ) no teor de sólidos totais.

Os queijos de ovelha são boas fontes de proteínas, energia, gordura, minerais e vitaminas. São ricos em ácidos graxos de cadeias curta e média, além de $C_{18: 1}$ e $C_{18: 2}$, que são benéficos à saúde. Entretanto, os componentes do leite e as condições em que se encontram nos queijos variam com o processo tecnológico utilizado (RAYNAL-LJUTOVAC et al., 2008; BERGAMINI et al., 2010). Além disso, devido ao perfil lipídico, ao tamanho dos glóbulos de gordura e aos altos teores de minerais (principalmente cálcio) e vitaminas (exceto a provitamina caroteno), o leite de ovelha torna-se mais saudável e de fácil digestão quando comparados ao leite bovino. Foram também identificados, neste alimento, peptídeos bioativos derivados de hidrólise enzimática das caseínas e das proteínas do soro, com propriedades antimicrobianas, antitrombóticas e auxiliares na prevenção de hipertensão arterial, além de outras funções (PARK et al., 2007).

Queijos originados do leite de ovelha apresentam, em geral, uma relativa ausência de gostos amargos, possivelmente devido às menores proporções de caseínas $\alpha_{s}$ (sua hidrólise enzimática gera frações peptídicas responsáveis por tais sabores desagradáveis) em relação às caseínas totais. A relação caseínas/proteínas totais situa-se entre $82 \%-83 \%$, enquanto que o teor de proteínas solúveis por litro de leite de ovelha é quase duas vezes maior que as proteínas solúveis do leite de vaca, o que torna comum a produção de queijos tipo ricota (ASSENAT, 1985). 
A densidade do leite, calculada a partir da determinação da massa volumétrica, está relacionada à riqueza de constituintes, entretanto, é necessário lembrar que a gordura do leite apresenta uma densidade inferior a 1,0 $\mathrm{mg} / \mathrm{mL}$ o que leva um leite rico em gordura a apresentar uma densidade diminuída (GOURSAUD, 1985). Na França, região de Roquefort, Assenat (1985) verificou que a densidade do leite de ovelha situa-se em torno de 1,036, com variação entre 1,034 e 1,038 $\mathrm{mg} / \mathrm{ml}$.

$\mathrm{O} \mathrm{pH}$ indica a qualidade do leite quanto a sua condição higiênica e de conservação. Um leite fresco normal deve apresentar um $\mathrm{pH}$ neutro com leve tendência ácida. $\mathrm{O} \mathrm{pH}$ diminui à medida que bactérias láticas presentes utilizam parte da lactose produzindo ácido lático. Um leite com $\mathrm{pH}<6,5$ é considerado um leite ácido. $\mathrm{O}$ leite mastítico apresenta característica alcalina $(\mathrm{pH}>7,0)$ enquanto que o colostro é acido, com pH próximo a 6,0 (GOURSAUD, 1985). O pH do leite de ovelha é praticamente o mesmo que o encontrado em leite de vaca, situando-se em torno de 6,65, apresentando pequena oscilação. A variação encontrada no leite da raça Lacaune, na região de Roquefort, foi de 6,60 a 6,68 (ASSENAT, 1985).

A acidez titulável, expressa convencionalmente em grau Dornic - 1으 corresponde a 0,1 g de ácido lático por litro de leite - estima o acúmulo de ácido lático proveniente da ação de bactérias láticas. A acidez titulável normal do leite significa que seus constituintes apresentam características ácidas que podem reagir com o hidróxido de sódio da solução Dornic e não que este leite apresente ácido lático (GOURSAUD, 1985). Segundo Assenat (1985) a variação para o leite de ovelha situa-se entre 18 ㅇ a 22 으.

O Índice Crioscópico ou Depressão do Ponto de Congelamento (DPC) é a medição da temperatura de congelamento do leite. É expressa em grau Hortvet (으) ou em grau Celsius (으), sendo que: $\mathrm{T}(\stackrel{\circ}{\circ} \mathrm{H})=1,0356 \times \mathrm{T}(\stackrel{\circ}{ } \mathrm{C})$.

Esta temperatura é decorrente da quantidade de água em relação aos constituintes solúveis e da gordura do leite, portanto, é um indicador de possível fraude por adição de água. Assenat (1985) cita uma estreita faixa de variação para o ponto crioscópico no leite da raça Lacaune, na região de Roquefort, oscilando de $0,570^{\circ} \mathrm{C}$ a $-0,575 \circ \mathrm{C}$.
O leite de pequenos ruminantes apresenta composição bioquímica diferenciada em relação ao leite bovino, o que lhe confere baixa estabilidade coloidal, como a precipitação das caseínas em leite de cabras em etanol $45 \%$ (RAYNAL-LJUTOVAC et al., 2007). Segundo Fava (2012) amostras do leite de ovelhas Lacaune do Rio Grande do Sul precipitaram em etanol $63,17 \pm 3,64 \%$, com forte correlação com a acidez titulável e moderada a forte correlação com o pH do leite.

\section{FATORES QUE INFLUENCIAM NA COMPOSIÇÃO DO LEITE DE OVELHA}

Dentre os fatores que influenciam na composição do leite de ovelha estão: a raça, a alimentação, a estação do ano, o estágio de lactação e o estado sanitário (HASSAN, 1995; CARLONI et al., 2010).

A produção de leite de ovelha pode ser dobrada em rebanhos de raças puras não especializadas com a introdução de raças leiteiras (raças mistas). Em poucos anos a produção média de leite de ovelha, nos EUA, passou de 76,9 kg por lactação (1996) para 223,5 kg (2000). A maior produção se deve à melhoria genética, com introdução de ovelhas especializadas para produção de leite (East Freasian) e ao manejo de desmame dos cordeiros (THOMAS et al., 2001).

Corrêa et al. (2006), no Uruguai, compararam ovelhas Corriedale com cruzas Corriedale $x$ Milchschaf (F1) e cruzas F1 $x$ Milchschaf, verificando significativo aumento de produção e de sólidos, quando utilizado cruzamentos com a raça especializada Milchschaf. Além da implicação do genótipo, também foi identificado efeito da condição corporal com consequência positiva desta sobre a produção e teor de gordura, além da constatação de que ovelhas primíparas produzem, em média, $37,3 \%$ menos leite. A morfologia do úbere também tem correlação positiva com a produção de leite e pode ser considerada como critério de seleção de ovelhas leiteiras, em programas específicos (AYADI et al., 2011).

As pastagens interferem diretamente na composição dos ácidos graxos, principalmente ácidos graxos poli-insaturados (PUFA Polyunsaturated Fatty Acids) e ácido linoleico conjugado (CLA - Conjugated Linoleic Acid). A criação a pasto, com alta relação fibra/energia, aumenta o teor de gordura e melhora a qualidade do queijo produzido (queijos mais suaves e com melhor consistência). Com a 
inclusão na dieta de 40 a $60 \%$ de concentrado, a gordura decresce lenta e linearmente, sendo observado um aumento da produção, enquanto que acima de $60 \%$ de concentrado, o teor de gordura decresce rapidamente (NUDDA et al., 2003; MORAND-FEHR et al., 2007; SANZ SAMPELAYO et al., 2007). Variações de produção e composição do leite de ovelha por influência do nível de fibra em detergente neutro (FDN), que influencia diretamente no consumo do alimento, também foram verificadas por Hübner et al. (2007).

Segundo Pulina et al. (2006), a nutrição das ovelhas causa grande e direto impacto sobre a composição do leite, alterando, principalmente, seus conteúdos de gordura e proteína. A concentração de gordura depende do balanço de energia líquida, mas a fibra na alimentação também tem papel importante, principalmente no perfil de ácidos graxos. A concentração de proteína varia menos que a de gordura, sendo mais importante neste caso, o balanço energético do que o perfil de aminoácidos ingerido.

A importância do estimulo da ejeção do leite em ovelhas foi observada por Ribeiro et al. (2007) em ovelhas Santa Inês não habituadas à ordenha e tratadas com ocitocina, onde a produção média aumentou $51,8 \%$, em relação às ovelhas sem o tratamento, enquanto 0 percentual de gordura aumentou de 4,96\% para $5,84 \%$.

Em estudo realizado por De La Fuente et al. (1997), comparou-se a produção, células somáticas, proteína e gordura entre as ordenhas da manhã e da tarde, verificando maiores valores para os três últimos na ordenha da tarde, atribuídos a um efeito de diluição, uma vez que verificaram uma maior produção de leite pela manhã.

A infecção da glândula mamária com consequente aumento de Contagem de Células Somáticas (CCS) promove a redução na produção de leite e de seus constituintes, principalmente a lactose. A proporção de caseínas sobre as proteínas totais diminui, enquanto a de proteínas solúveis aumenta (LEITNER et al., 2004; LEITNER et al., 2011). Nestes casos, além do aumento da presença da enzima plasmina, verificaram um grande aumento de sua atividade enzimática.

No sul da Itália, Sevi et al. (2004) analisaram amostras de leite de ovelhas Comisana em diferentes períodos de lactação ao longo das estações do ano. Durante a primavera/verão os animais pastavam e recebiam suplemento com feno e concentrado, já durante o outono/inverno os animais receberam apenas feno e concentrado. Das 240 amostras analisadas, os autores observaram que o leite oriundo de ovelhas que haviam parido no inverno, apresentou menores teores de gordura e proteínas em comparação o leite de ovelhas que pariram no outono $(6,71 \%$ x 6,93\% e $5,15 \%$ x $5,39 \%$, respectivamente), bem como a deterioração do coalho e das características de higiene. Constaram que independente da época do parto, a contagem de células somáticas mostrou-se maior no final, em comparação ao início e meio, da lactação $(6,16 ; 5,93$ e 5,87 $\log 10$ células somáticas $/ \mathrm{ml}$, respectivamente). Por fim, sugerem que a qualidade do leite ovino é diretamente afetada, por mudanças sazonais do clima e estado metabólico, como o avanço da lactação.

\section{FATORES DE QUALIDADE RELACIONADOS À HIGIENE E SANIDADE DO REBANHO}

A qualidade do leite de ovelha está ligada às suas características sanitárias, nutricionais, tecnológicas e a aspectos relacionados aos queijos - sensoriais, reológicos e gastronômicos (MORAND-FEHR et al., 2007).

Sob o aspecto higiênico-sanitário, o primeiro fator que surge, e requer certa atenção, refere-se às células somáticas. Pequenos ruminantes - cabras e ovelhas - sadios apresentam níveis basais de CCS muito mais elevado do que os verificados em vacas sadias ( 300.000 cel./ml para cabras, $\sim 200.000$ cel. $/ \mathrm{ml}$ para ovelhas e $\sim 70.000$ cel./ml para vacas). Portanto, o nível de células somáticas em leite proveniente de úberes com infecção é, geralmente, muito mais elevado em caprinos e ovinos do que em vacas. Desta forma, um sistema de classificação do leite de ovinos, baseado em CCS, deve ser ajustado especificamente à situação particular dessa espécie, e não ser simplesmente adaptado a partir dos critérios estabelecidos para vacas (RAYNAL-LJUTOVAC et al., 2007).

A contagem de células somáticas de vacas, cabras e ovelhas, nos EUA, tem como limite, $750.000 \mathrm{cel} . / \mathrm{ml}$ em vacas e 1.000 .000 cel./ml para cabras e ovelhas, embora os produtores norte-americanos de leite de pequenos ruminantes tenham dificuldades para cumprir esta exigência. Na União Europeia o limite de CCS em vacas é de 400.000 cel. $/ \mathrm{ml} \mathrm{e}$ 
não há limite legal estabelecido para a CCS em leite de cabra e ovelha (PAAPE et al., 2007).

Em leite bovino, foi observado que o grau de especialização e tecnificação dos sistemas produtivos interferem positivamente na CCS (ZANELA et al., 2006), sendo o mesmo observado em leite de ovelha. Foram considerados fatores importantes para baixa CCS em ovelhas, as práticas higiênicas e de manejo, como pósdipping, aplicação do California Mastit Test (CMT), utilização de terapia nas ovelhas secas e manutenção de registros de animais com mastite clínica (MOLINA et al., 2010).

A correta limpeza e desinfecção dos tetos, com água e pré-dipping com soluções desinfetantes, são suficientes para reduzir em até $90 \%$ a contaminação dos mesmos. Estas medidas são muito importantes na qualidade final do leite ordenhado, na prevenção de mastite e como estimulante da ejeção do leite (BRITO et al., 2000; AMARAL et al., 2004).

Muitos fatores não infecciosos, em cabras e ovelhas, são responsáveis pela elevação da CCS. Animais em fase final de lactação, estresse nutricional e carência de algumas vitaminas, por exemplo, apresentam forte elevação fisiológica da CCS (BRITO et al., 2006; PULINA et al., 2006; RAYNAL-LJUTOVAC et al., 2007; LEITNER et al., 2011).

A alta CCS associada à infecção intramamária, causa prejuízos à produção leiteira e à indústria. Os efeitos da alta CCS no leite de ovelha sobre os derivados lácteos não estão bem claros. Enquanto algumas pesquisas não encontraram diferenças significativas na composição e nas características sensoriais entre os queijos produzidos com leite de ovelha contendo baixas $\left(<5 \times 10^{5} \mathrm{cel} . / \mathrm{ml}\right)$ e altas $\left(>1,5 \times 10^{6}\right.$ cel./ml) CCS, outros estudos apontam diferenças nestes parâmetros (RAYNAL-LJUTOVAC et al., 2007). O leite de ovelha apresenta menor tempo de coagulação, melhor rendimento de coalhada e produz um coalho mais firme que o leite de vaca (BENCINI, 2002), mas o processo infeccioso da glândula mamária resulta em uma redução da produção de leite, do rendimento de queijo e da firmeza do coalho, tornando-o mais frágil e reduzindo a sinérese, ao mesmo tempo em que aumenta o tempo de coagulação (LEITNER et al., 2011).

A mastite em ovelhas provoca a redução de sólidos, mais acentuadamente de lactose e gordura. As caseínas reduzem sensivelmente, enquanto as proteínas do soro aumentam (MERIN et al., 2004) o que também provoca a redução na produção da coalhada e aumento no tempo de coagulação (MERIN et al., 2004).

Com a mastite ocorre a alteração do perfil enzimático e salino do leite de ovelha, elevação do $\mathrm{pH}$, além da redução da relação caseínas/proteínas totais. Segundo Leitner et al. (2004), o sistema plasmina, em especial, apresenta aumento de atividade da plasmina (em $150 \%$ ou mais) e do ativador de plasminogênio, enquanto ocorre a redução da atividade de plasminogênio e da relação plasminogênio/plasmina. A proteólise provocada pela ação da plasmina em leite de ovelha é muito superior a verificada em vacas, observando-se 2,4 vezes mais proteose-peptonas em leite de ovelhas com mastite em relação ao de ovelhas sadias. A degradação das caseínas acaba por expor grupos fosforilados, com efeito quelante sobre $\mathrm{O} \mathrm{Ca}^{+2}$, reduzindo sua atividade. Este processo inicia ainda dentro do úbere, no intervalo entre ordenhas. Como a fase primária da coagulação das caseínas é muito sensível a variações da composição do leite e da atividade do $\mathrm{Ca}^{+2}$, ocorre o aumento do tempo de coagulação, redução da sinérese $e$ enfraquecimento do coalho. A ação da plasmina sobre a $\beta$-caseína, principalmente, produz peptídeos, por exemplo, $\beta-C N$ 1-28, que regulam as funções da glândula mamaria bloqueando os canais de $\mathrm{K}^{+}$, reduzindo o teor de lactose e outros componentes osmóticos no leite (LEITNER et al, 2004; LEITNER et al., 2011), além de limitar, ainda mais, o rendimento da coalhada pela solubilização de partes de $\beta$-caseína hidrolisadas (FOX; MCSWEENEY, 1998). Após a coagulação das caseínas a plasmina, o plasminogênio e o ativador de plasminogênio ficam retidos no coalho, enquanto seus inibidores são solubilizados no soro (Figura 1). Isso provoca a aceleração das proteólises primárias durante o período de maturação do queijo (FOX; MCSWEENEY, 1998) podendo provocar alterações de aspecto, sabor e textura no produto final. 


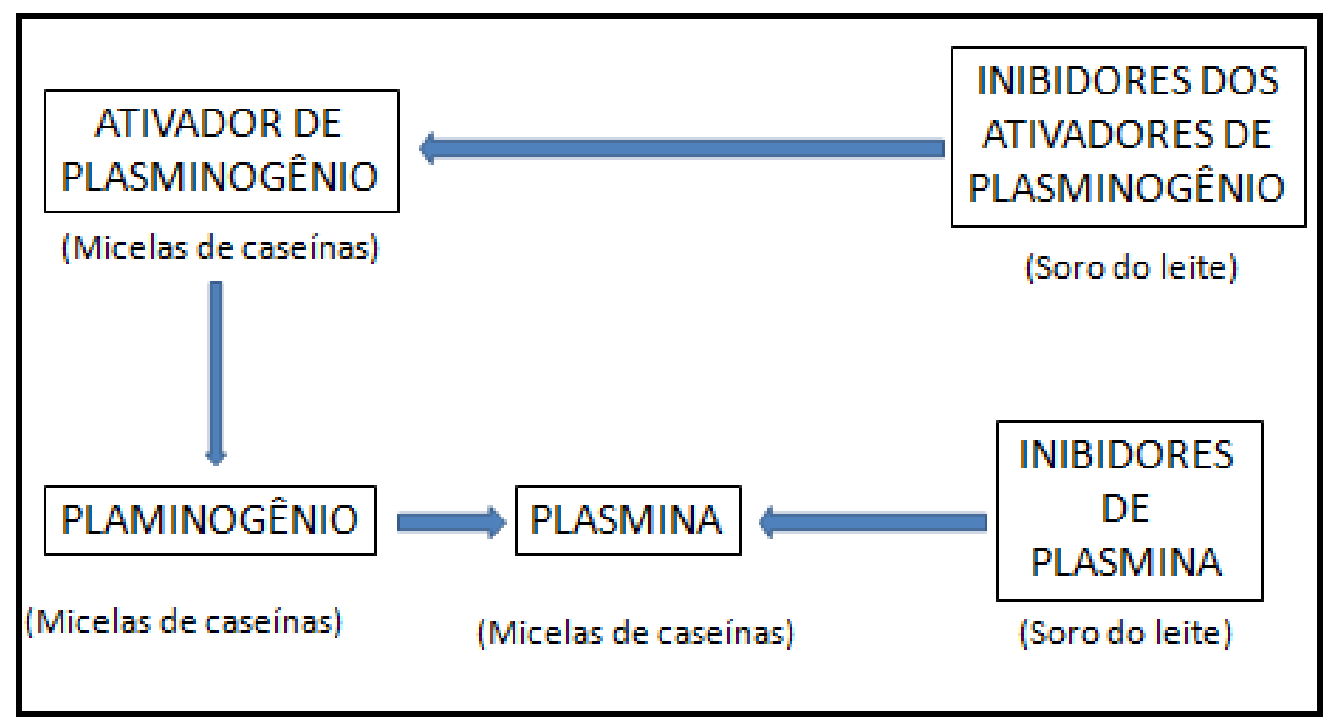

Figura 1. Representação esquemática do sistema plasmina no leite. Fonte: adaptado de Fox e McSweeney (1998).

Segundo Assenat (1985), a microbiologia do leite de ovelha é tratada do mesmo modo que a dos outros leites. As contaminações do leite de origem mamária tem pouca importância em rebanhos sadios, entretanto, o rebanho pode, em alguns casos, ser portador de Brucella melitensis ou B. abortus e transmiti-la pelo leite. Como em todos os leites, as contaminações são provenientes do ambiente e condições de ordenha.

Os riscos de contaminação do leite de ovelha são sensivelmente maiores do que ocorre com leite de vaca uma vez que é necessário um número muito maior de animais ordenhados dez a quinze vezes mais - para se obter o mesmo volume de leite, em relação ao de vaca (COTTIER, 1985).

Sob 0 aspecto da qualidade microbiológica, a contagem de microrganismos mesófilos é o único controle oficial da qualidade do leite, justamente por serem responsáveis pela rápida acidificação e degradação do leite quando este não é obtido de forma higiênica e/ou armazenado por tempo e temperatura inapropriados. Entretanto, também se faz importante atentar para a alta contagem de psicrotróficos nas amostras analisadas. Diversos microrganismos, deste grupo, são frequentemente encontrados em leite cru, como os gêneros: Enterococcus, Lactococcus, Streptococcus, Leuconostoc, Lactobacillus,
Mycobacterium, Micrococcus e Pseudomonas, entre outros, produtores de proteases, que levam a perda de compostos nitrogenados para o soro, reduzindo o rendimento de fabricação e queijos e provocando alterações das características de coagulação das proteínas. Além disso, também produzem lípases que hidrolisam as gorduras, levando ao processo de rancificação (JAY, 2005). Estes processos enzimáticos podem levar às alterações de cor, sabor e textura dos queijos produzidos (FRANCO; LANDGRAF, 2008).

Entretanto, para melhor identificação do perfil de microrganismos contaminantes do leite, é possível realizar contagem de outros grupos de bactérias, os chamados microrganismos indicadores de contaminação fecal, sendo o principal a Escherichia coli, ou de qualidade higiênico-sanitária do alimento, como os Staphylococcus spp., enterobactérias e coliformes totais. Estes últimos são amplamente difundidos no ambiente, portanto a alta contagem deles representa deficiência na higiene (JAY, 2005; FRANCO; LANDGRAF, 2008).

É esperada a presença de Staphylococcus spp. em alimentos de origem animal, a não ser que tenha sido realizado tratamento térmico. Após 12 horas de incubação já começam a serem produzidas toxinas termoestáveis por algumas cepas e a partir de uma população de $10^{4}$ UFC/mL, a produção pode ser intensa (JAY, 2005). 
Elevadas concentrações de microrganismos indicadores de qualidade representam risco à saúde pública. Constatou-se a presença de Staphylococcus spp. em $100 \%$ de 80 amostras de leite de vaca mantidos a 4 으 por 48 horas em Minas Gerais, com a identificação de enterotoxina estafilocócica e de toxina da síndrome do choque tóxico, produzidas por estas bactérias e responsáveis por muitos surtos de intoxicação estafilocócica (LAMAITA et al., 2005). Sabe-se que a principal fonte de enzimas proteolíticas e lipolíticas vem dos psicrotróficos, porém também foi constatada a produção, destas enzimas deteriorantes, por coliformes de diversas espécies, inclusive termotolerantes, estafilococos coagulase positiva e Enterococcus spp. (TEBALDI et al., 2008). Por este motivo, são de grande importância baixas contagens iniciais de microrganismos contaminantes e o tempo e a temperatura apropriados de armazenagem.

\section{CONSIDERAÇÕES FINAIS}

A ovinocultura leiteira no Brasil vem crescendo nos últimos anos, em especial, pelas importantes características do leite de ovelha que atraem novos produtores para este ramo do agronegócio. O elevado potencial em gerar derivados lácteos, como queijos, iogurtes e manteigas, de alta qualidade e rendimento são fatores bastante relevantes. Em decorrência das altas concentrações de sólidos totais como proteínas, lipídios e sais minerais o leite de ovelha torna-se diferenciado das demais espécies. Atualmente, quando comparado com os estudos da literatura internacional, ainda são poucos os trabalhos sobre qualidade $e$ composição do leite ovino produzido no Brasil, o que demonstra a necessidade de novas pesquisas a cerca do tema. Observa-se também, que a legislação brasileira vigente (IN 62/2011), não é totalmente adequada e específica para o leite de ovelha, ou seja, o insumo obedece a regras e normas pouco adequadas à espécie, indicando a necessidade de aprimoramento deste quesito.

\section{REFERÊNCIAS}

AGUINSKI, M. Produtores de ovinos do RS e SC aumentam a renda com derivados do leite. $2011 . \quad$ Disponível em: <http://www.cabanhadedoverde.com.br/>. Acesso em: 01 jul. 2014.

AMARAL, L. A.; ISA, H.; DIAS, L. T.; ROSSI JUNIOR, O. D.; NADER FILHO, A. Avaliação da eficiência da desinfecção de teteiras e dos tetos no processo de ordenha mecânica de vacas. Pesq. Vet. Bras., v.24, n.4, p.173-177, 2004. http://dx.doi.org/10.1590/S0100736X2004000400001.

ASSENAT, L. O leite de ovelha - composição e propriedades. In: LUQUET, F.M. O leite: do úbere à fábrica de laticínios. Mem Martins: Publicações Europa-América, v. 1, parte II, cap. 1, p. 335-374, 1985.

AYADI, M.; SUCH, X.; EZZEHIZI, N.; ZOUARI, M.; NAJAR, T.; BEN M'RAD, M.; CASALS, R. Relationship between mammary morphology traits and milk yield of Sicilo-Sarde dairy sheep in Tunisia. Small Ruminant Res, v. 96, n. 1, p. 41-45, 2011.

http://dx.doi.org/10.1016/j.smallrumres.2010.10. 013.

BARBANO, D. M.; LYNCH, J. M. Major advances in testing of dairy products: milk component and dairy product attribute testing. J Dairy Sci, v. 89, n. $4, \quad$ p. $1189-1194,2006$. http://dx.doi.org/10.3168/jds.S00220302(06)72188-9

BARILLET, F.; MARIE, C.; JACQUIN, M.; LAGRIFFOUL, G.; ASTRUC, J. M. The french lacaune dairy sheep breed: use in France and abroad in the last 40 years. Livest Prod Sci, v. 71, n. 1, p. 17-29, 2001. http://dx.doi.org/ 10.1016/S0301-6226(01)00237-8

BENCINI, R. Factors affecting the clotting properties of sheep milk. J Sci Food Agr, v. 82, n. 7 p. $\quad$ 705-719, 2002. http://dx.doi.org/10.1002/jsfa.1101

BERGAMINI, C. V.; WOLF, I. V.; PEROTTI, M. C.; ZALAZAR, C. A. Characterisation of biochemical changes during ripening in Argentinean sheep cheeses. Small Ruminant Res, v. 94, n. 1-3, p. 7989 ,

2010. http://dx.doi.org/10.1016/j.smallrumres.2010.07. 004

BRASIL. Ministério da Agricultura, Pecuária e Abastecimento. Decreto no 30.691, de 29 de março de 1952. Aprova o novo Regulamento da Inspeção Industrial e Sanitária de Produtos de Origem Animal - RIISPOA. Diário Oficial [da] União, Brasília, DF, 07 jul. 1952, Seção 1, p. $10785 . \quad$ Disponível em: <http://www.agricultura.gov.br/legislacao>. Acesso em: 27 jan. 2011.

BRASIL. Ministério da Agricultura, Pecuária e Abastecimento. Portaria no 166, de 05 de maio de 1998. Cria Grupo de Trabalho para analisar e propor programa e medidas visando ao aumento da competitividade e à modernização do setor 
produtivo de leite e derivados no Brasil. Diário Oficial [da] União, Brasília, DF, 06 maio 1998. Disponivel em: <http://www.agricultura.gov.br/legislacao>. Acesso em: 19 jul. 2011.

BRASIL. Ministério da Agricultura e do Abastecimento. Instrução Normativa no 37, de 31 de outubro de 2000. Regulamento Técnico de Identidade e Qualidade de Leite de Cabra. Diário Oficial [da] União, Brasília, DF, 08 nov. 2000. Disponível em: <http://www.agricultura.gov.br/legislacao>.

Acesso em: 19 jul. 2011.

BRASIL. Ministério da Agricultura, Pecuária e Abastecimento. Instrução Normativa no 51, de 18 de setembro de 2002. Aprova os Regulamentos Técnicos de Produção, Identidade e Qualidade do Leite tipo A, do Leite tipo B, do Leite tipo C, do Leite Pasteurizado e do Leite Cru Refrigerado e o Regulamento Técnico da Coleta de Leite Cru Refrigerado e seu Transporte a Granel. Diário Oficial [da] União, Brasília, DF, 20 set. 2002. Disponível em: <http://www.agricultura.gov.br/legislacao>. Acesso em: 19 jul. 2011.

BRASIL. Ministério da Agricultura, Pecuária e Abastecimento. Instrução Normativa no 62, de 29 de dezembro de 2011. Altera a Instrução Normativa MAPA no 51, de 18 de setembro de 2002. Diário Oficial [da] União, Brasília, DF, 30 dez. 2011. Disponível em: <http://www.agricultura.gov.br/legislacao>.

Acesso em: 13 jan. 2012.

BRASIL. Ministério da Agricultura Pecuária e Abastecimento. Relação de Produtos Habilitados para Exportação para o Brasil por País. <http://bi.agricultura.gov.br/reports/rwservlet?si gsif_cons\&prod_hab_exp_pais.rdf\&p_id_pais $=18$ 9\&p_id_area $=\& p \_i d \_p r o d u t o=\& p \_s e r i a l=124219$ 288\&paramform=no>. Acessado em: 27 jul. 2015. BRITO, J. R. F.; BRITO, M. A. V. P.; VERNEQUE, R. $S$. Contagem bacteriana da superfície de tetas de vacas submetidas a diferentes processos de higienização, incluindo a ordenha manual com participação do bezerro para estimular a descida do leite. Ciência Rural, v. 30, n. 5, p. 847-850, $2000 . \quad$ http://dx.doi.org/10.1590/S010384782000000500018.

BRITO, M. A.; GONZÁLEZ, F. D.; RIBEIRO, L. A.; CAMPOS, R.; LACERDA, L.; BARBOSA, P. R.; BERGMANN, R. Composição do sangue e do leite em ovinos leiteiros do sul do Brasil: variações na gestação e na lactação. Ciência Rural, v. 36, n. 3, p.942-948,

2006.
http://dx.doi.org/10.1590/S0103-

84782006000300033

CAMPOS, L. Aspectos benéficos do leite de ovelha e seus derivados. Casa da ovelha, Bento Gonçalves, jan. 2011. Disponível em: <http://www.casadaovelha.com.br>. Acesso em: 05 maio 2011.

CARLONI, M.; FEDELI, D.; ROSCIONI, T.; GABBIANELLI, R.; FALCIONI, G. Seasonal variation of fat composition in sheep's milk from areas of central Italy. Mediterr J Nutr Metab, v. 3, n. 1, p.55-60, $2010 . \quad$ http://dx.doi.org/ 10.1007/s12349-009-0057-0

CORRÊA, G. F.; OSÓRIO, M. T. M.; KREMER, R.; OSÓRIO, J. C. S.; PERDIGÓN, F.; SOSA, L. Produção e composição química do leite em diferentes genótipos ovinos. Ciência Rural, v. 36, n. 3, p.936941, 2006. http://dx.doi.org/10.1590/S010384782006000300032.

COTTIER, H. O leite de ovelha - produção do leite de ovelha. In: LUQUET, F.M. O leite: do úbere à fábrica de laticínios. Mem Martins: Publicações Europa-América, v. 1, parte II, cap. 2, p. 375-390, 1985.

DE LA FUENTE, L. F.; SAN PRIMITIVO, F.; FUERTES, J. A.; GONZALO, C. Daily and between-milking variations and repeatabilities in milk yield, somatic cell count, fat, and protein of dairy ewes. Small Ruminant Res, v. 24, n. 2, p. 133-139, 1997. http://dx.doi.org/10.1016/S0921-4488(96)009273.

FAO. FAO STAT Database Collections. 2013. Disponível em: <http://faostat.fao.org/site/339/default.aspx>. Acesso em: 01 jun. 2013.

FAO. Global Milk Production and Consumption. $2014 . \quad$ Disponível em:< http://chartsbin.com/view/1492>. Acesso em: 27 jul. 2015.

FAO. Dairy production and products. Small ruminants. 2015. Disponível em $:<h t t p: / / w w w . f a o . o r g / a g r i c u l t u r e / d a i r y-$ gateway/milk-production/dairy-animals/smallruminants/en/>. Acesso em: 27 jul. 2015.

FAVA, L. W. Caracterização físico-química do leite de ovelhas da raça Lacaune e análise do rendimento de coalhada com caracterização física do soro obtido. 2012. 73 f. Dissertação (Mestrado em Ciências Veterinárias) Universidade Federal do Rio Grande do Sul. Porto Alegre, 2012. Disponível em: <http://www.lume.ufrgs.br/bitstream/handle/10 
183/62057/000868624.pdf?sequence=1>. Acesso em: 19 mar. 2013.

FOX, P. F.; MCSWEENEY, P. L. H. Dairy chemistry and biochemistry. London: Thomson Science, 1998. $478 \mathrm{p}$.

FRANCO, B.D.G.M.; LANDGRAF, M. Microbiologia dos alimentos. São Paulo: Atheneu, 2008. 182 p.

GOURSAUD, J. O leite de vaca - Composição e propriedades físico-químicas. In: LUQUET, F.M. $\mathbf{O}$ leite: do úbere à fábrica de laticínios. Mem Martins: Publicações Europa-América, 1985, v. 1, parte I, cap.1, p. 31-130.

GRIEBLER, L. A ovinocultura leiteira no Brasil. 2012 Disponível em: http://www.farmpoint.com.br/radarestecnicos/sistemas-de-producao/a-ovinoculturaleiteira-no-brasil-79849n.aspx.> Acesso em: 28 jul 2015.

HAENLEIN, G. F. W. About the evolution of goat and sheep milk production. Small Ruminant Res, v. 68, n. 1-2, p. 3-6, 2007. http://dx.doi.org/10.1016/j.smallrumres.2006.09. 021.

HASSAN, H. A. Effects of crossing and environmental factors on production and some constituents of milk in Ossimi and Saidi sheep and their crosses with Chios. Small Ruminant Res, v. 18, n. 2, p. 165-172, 1995. http://dx.doi.org/10.1016/0921-4488(95)00684-

D

HÜBNER, C. H.; PIRES, C. C.; GALVANI, D. B.; CARVALHO, S.; WOMMER, T. P. Consumo de nutrientes, produção e composição do leite de ovelhas alimentadas com dietas contendo diferentes níveis de fibra em detergente neutro. R. Bras. Zootec., v. 36, n. 6, p. 1882-1888, 2007. http://dx.doi.org/10.1590/S151635982007000800023.

IBGE. Produção da Pecuária Municipal 2011. Rio de Janeiro: IBGE, v. 39, p. 1-63, 2012.

JAY, J. M. Microbiologia de alimentos. 6. ed. Porto Alegre: Artmed, 2005. 711p.

LAMAITA, H. C.; CERQUEIRA, M. M. O. P.; CARMO, L. S.; SANTOS, D. A.; PENNA, C. F. A. M.; SOUZA, M. R. Contagem de Staphylococcus sp. e detecção de enterotoxinas estafilocócicas e toxina da síndrome do choque tóxico em amostras de leite cru refrigerado. Arq. Bras. Med. Vet. Zootec., v. 57, n. 5, p. 702-709, 2005. http://dx.doi.org/10.1590/S0102-

09352005000500017.

LEITNER, G.; CHAFFER, M.; SHAMAY, A.; SHAPIRO, F.; MERIN, U.; EZRA, E.; SARAN, A.; SILANIKOVE,
N. Changes in Milk Composition as Affected by Subclinical Mastitis in Sheep. J Dairy Sci, v. 87, n.1, p.46-52, 2004. http://dx.doi.org/10.3168/jds.S00220302(04)73140-9

LEITNER, G.; MERIN, U.; SILANIKOVE, N. Effects of glandular bacterial infection and stage of lactation on milk clotting parameters: Comparison among cows, goats and sheep. Int Dairy J., v.21, n.4, p.279-285, 2011. http://dx.doi.org/10.1016/j.idairyj.2010.11.013

MADALENA, F.E. Valores Econômicos para a Seleção de Gordura e Proteína do Leite. Rev. Bras. Zootec, v. 29, n. 3, p. 678-684, 2000. http://dx.doi.org/10.1590/S151635982007000900010.

MERIN, U.; SILANIKOVE, N.; SHAPIRO, F.; BERNSTEIN, S.; LEITNER, G. Changes in milk composition as affected by subclinical mastitis in sheep and goats. South African Journal of Animal Science, v. 34, n. Supplement 1, p. 188-191, 2004. MOLINA, A.; YAMAKI, M.; BERRUGA, M.; ALTHAUS, R. L.; MOLINA, M. P. Management and sanitary practices in ewe dairy farms and bulk milk somatic cell count. Span J Agric Res, v. 8, n. 2 , p. 334-341, 2010. http://dx.doi.org/ 10.5424/sjar/2010082-1213

MORAND-FEHR, P.; FEDELE, V.; DECANDIA, M.; LE FRILEUX, Y. Influence of farming and feeding systems on composition and quality of goat and sheep milk. Small Ruminant Res, v. 68, n. 1-2, p. 20-34, $2007 . \quad$ http://dx.doi.org/ 10.1016/j.smallrumres.2006.09.019

NASCIMENTO, R. Raças novas no campo Ovinocultores do sul e do sudeste do Brasil melhoram a renda produzindo leite para a fabricação de queijos finos. Globo Rural. Disponível em: <http://revistagloborural.globo.com/Revista/Co mmon/0,,ERT184658-18282,00.html>. Acesso em: 10 jan. 2013.

NUDDA, A.; MELE, M.; BATTACONE, G.; USAI, M. G.; MACCIOTTA, N. P. P. Comparison of conjugated linoleic acid (CLA) content in milk of ewes and goats with the same dietary regimen. Ital J Anim Sci, v. 2, n. Supl. 1, p. 515-517, 2003. http://dx.doi.org/10.4081/ijas.2003.2137

PAAPE, M. J.; WIGGANS, G. R.; BANNERMAN, D. D.; THOMAS, D. L.; SANDERS, A. H.; CONTRERAS, A.; MORONI, P.; MILLER, R. H. Monitoring goat and sheep milk somatic cell counts. Small Ruminant Res, v. 68, n. 1-2, p. 114-125, 2007. http://dx.doi.org/10.1016/j.smallrumres.2006.09. 014 
PARK, Y. W.; JUÁREZ, M.; RAMOS, M.; HAENLEIN, G. F. W. Physico-chemical characteristics of goat and sheep milk. Small Ruminant Res, v. 68, n. 12, p.88-113, 2007. http://dx.doi.org/10.1016/j.smallrumres.2006.09. 013

PULINA, G.; NUDDA, A.; BATTACONE, G.; CANNAS, A. Effects of nutrition on the contents of fat, protein, somatic cells, aromatic compounds, and undesirable substances in sheep milk. Anim Feed SciTech, v. 131, n. 2-4, p. 255291, 2006. http://dx.doi.org/10.1016/j.anifeedsci.2006.05.0 23

RAYNAL-LUUTOVAC, K.; LAGRIFFOUL, G.; PACCARD, P.; GUILLET, I.; CHILLIARD, Y. Composition of goat and sheep milk products: An update. Small Ruminant Res, v. 79, n. 1, p.57-72, 2008.

http://dx.doi.org/10.1016/j.smallrumres.2008.07. 009

RAYNAL-LUUTOVAC, K.; PIRISI, A.; CRÉMOUX, R.; GONZALO, C. Somatic cells of goat and sheep milk: Analytical, sanitary, productive and technological aspects. Small Ruminant Res, v. 68, n. 1-2, p. 126-144, 2007. http://dx.doi.org/ 10.1016/j.smallrumres.2006.09.012

RIBEIRO, L. C.; PÉREZ, J. R. O.; CARVALHO, P. H. A.; SILVA, F. F.; MUNIZ, J. A.; OLIVEIRA JÚNIOR, G. M.; SOUZA, N. V. Produção, composição e rendimento em queijo do leite de ovelhas Santa Inês tratadas com ocitocina. Rev. Bras. Zootec, v.36, n.2, p.438-444, 2007.

ROHENKOHL, J. E.; CORRÊA, G. F.; AZAMBUJA, D. F.; FERREIRA, F. R. O agronegócio de leite de ovinos e caprinos. Indic Econ FEE, v. 39, n. 2, p. 97-114, 2011.

SEAPA. Assessoria de Comunicação Social. 2013. Minas Gerais terá produção de queijo à base de leite de ovelha com inspeção federal. Disponível em:< http://www.farmpoint.com.br/cadeiaprodutiva/giro-de-noticias/minas-gerais-teraproducao-de-queijo-a-base-de-leite-de-ovelhacom-inspecao-federal-83480n.aspx.>. Acessado em: 27 jul. 2015.

SANZ SAMPELAYO, M. R.; CHILLIARD, Y.; SCHMIDELY, PH.; BOZA, J. Influence of type of diet on the fat constituents of goat and sheep milk. Small Ruminant Res, v. 68, n. 1-2, p. 42-63, 2007.

http://dx.doi.org/10.1016/j.smallrumres.2006.09. 017

SCINTU, M. F.; PIREDDA, G. Typicity and biodiversity of goat and sheep milk products.
Small Ruminant Res, v. 68, n. 1-2, p. 221-231, 2007.

http://dx.doi.org/10.1016/j.smallrumres.2006.09. 005

SEVI, A.; ALBENZIO, M.; MARINO, R.; SANTILLO, A.; MUSCIO, A. Effects of lambing season and stage of lactation on ewe milk quality. Small Ruminant Res, v. 51, n. 3, p. 251-259, 2004. http://dx.doi.org/10.1016/S0921-4488(03)001962

TALEVSKI, G.; ČOBANOVA-VASILEVSKA, R.; SRBINOVSKA, S.; SIRETA, Z. Quality of the sheep milk as a raw material in dairy industry of Macedonia. Biotechnology in Animal Husbandry, v. 25, n. 5-6, p. 971-977, 2009.

TEBALDI, V. M. R.; OLIVEIRA, T. L. C.; BOARI, C. A.; PICCOLI, R. H. Isolamento de coliformes, estafilococos e enterococos de leite cru provenientes de tanques de refrigeração por expansão comunitários: identificação, ação lipolítica e proteolítica. Ciênc. Tecnol. Aliment, v. 28, n. 3, p. 753-760, 2008. http://dx.doi.org/10.1590/S0101-

20612008000300036.

THOMAS, D. L.; BERGER, Y. M.; MCKUSICK, B. C. Effects of breed, management system, and nutrition on milk yield and milk composition of dairy sheep. J Anim Sci, v. 79, n. E-Suppl., p. E16E20, 2001. http://dx.doi.org/10.2134/jas2001.79E TICIANI, E.; SANDRI, E. C.;SOUZA, J; BATISTEL, F.; OLIVEIRA, D.E. Lactation persistency and milk composition in Lacaune and East Friesian dairy ewes. Ciência Rural, v.43, n.9, p1650-1653, 2013. http://dx.doi.org/10.1590/s0103-

84782013000900018

WOEHL, O. Produtores de leite de ovelha discutem produção de leite em pó. Biotecnologia Rural.

<https://rotabiotecanimal.wordpress.com/2011/ 03/28/produtores-de-leite-de-ovelha-discutem-aproducao-de-leite-em-po/ >. Acesso em: 28 jul. 2015.

ZANELA, M. B.; FISCHER, V.; RIBEIRO, M. E. R.; STUMPF JUNIOR, W.; ZENELA, C.; MARQUES, L. T.; MARTINS, P. R. G. Qualidade do leite em sistemas de produção na região Sul do Rio Grande do Sul. Pesq. Agropec. Bras., v. 41, n. 1, p. 153-159, jan. 2006. $\quad$ http://dx.doi.org/10.1590/S0100204X2006000100021 
Recebido para publicação em 04/08/2014

Revisado em 29/07/2015

Aceito em 15/06/2016 
Tabela 5. Consolidação de dados da literatura.

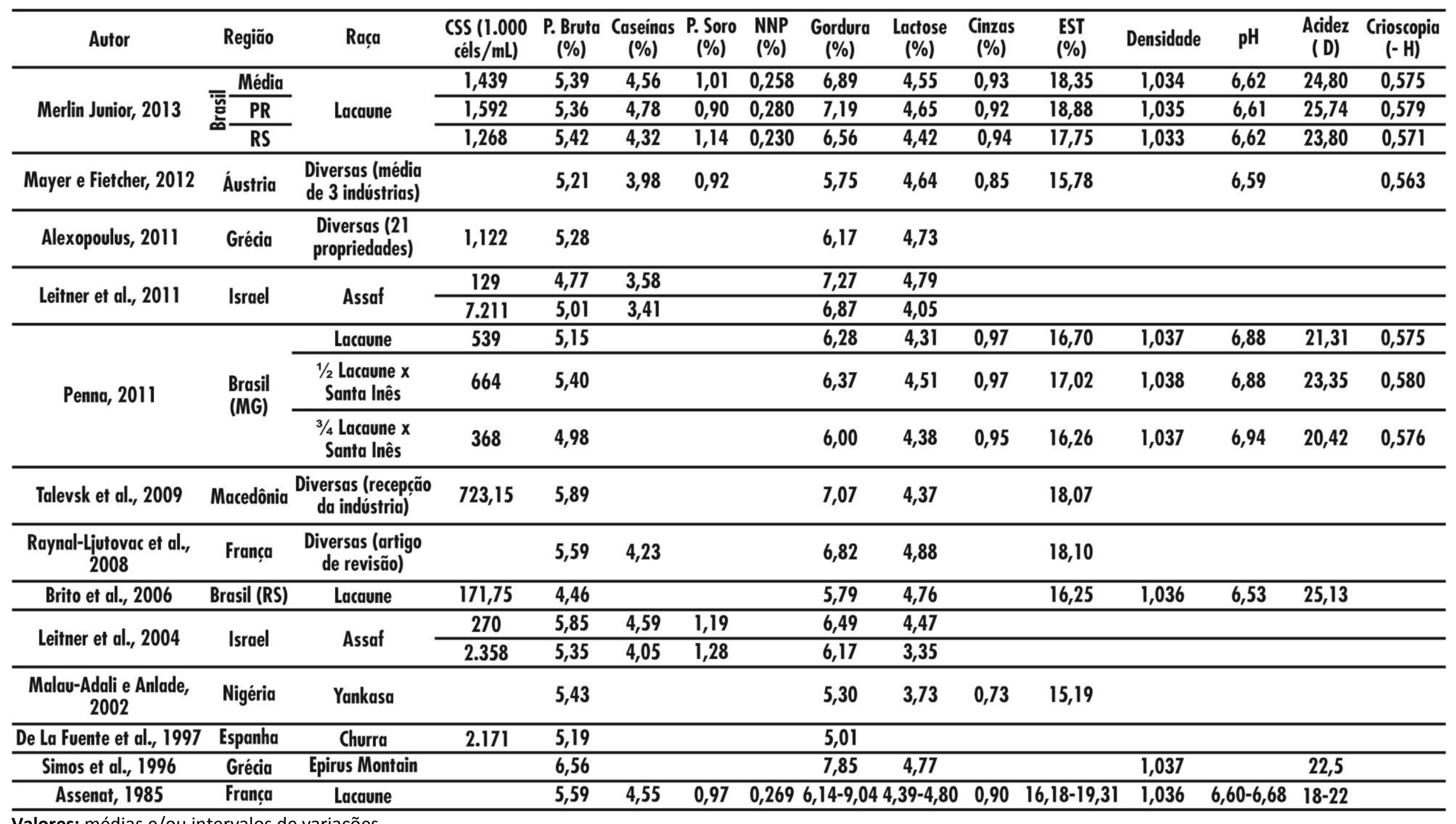

